\title{
Exploring Deliberate Practice \& the Use of Skill Sheets in the Collegiate Leadership Competition
}

\author{
Scott J. Allen \\ Associate Professor of Management \\ John Carroll University \\ Daniel M. Jenkins \\ Associate Professor of Leadership \& Organizational Studies \\ University of Southern Maine \\ Bela Krizanovic \\ Executive Director \\ Collegiate Leadership Competition
}

\begin{abstract}
Little has been written about the use of skill sheets in leadership education and this paper demonstrates how they have been implemented in one specific context. Used in a number of domains (e.g., karate, cardiopulmonary resuscitation) skill sheets are checklists or rubrics that record skill performance. The use of skill sheets in leadership learning and education is a critical step in our efforts to grow as a discipline. Founded in 2015, the Collegiate Leadership Competition has incorporated the use of skill sheets in skill development, assessment of learning, and curriculum design.

\section{Introduction}

The Collegiate Leadership Competition (CLC) was founded to disrupt current approaches to leadership learning and education and in many ways, to explore several dimensions of the National Leadership Education Research Agenda 2013-2018: Providing Strategic Direction for the Field of Leadership Education (Andenoro, Allen, Haber-Curran, Jenkins, Sowcik, Dugan, \& Osteen, 2013). CLC provides the space for deliberate practice (see Ericsson \& Pool, 2016) of leadership. In addition, students who participate in CLC stretch the boundaries of their leadership knowledge, skills, and abilities. In its fourth year, CLC curriculum designers continue to explore the role of deliberate practice in leadership education.

An important dimension of leadership education is the domain of skill building-yet surprisingly little is devoted to the topic in the leadership literature. Perhaps, because the activity of truly building skills takes time, practice, coaching, and feedback. As a result, most leadership education stays in the domain of conceptual understanding (the cognitive domain) and personal growth and development (the humanistic domain) (Allen \& Shehane, 2016). And while many leadership educators trumpet our "experiential learning" approach, often, our experiential activities do not result in true skill development. If they did, our literature would be filled with empirical studies of development and growth in skill. As a result, we often rely upon surveys and personal accounts of growth and development. This reality is an opportunity. Truly developing skill among students in realms such as negotiation, conflict management, problem solving, and
\end{abstract}


ethical decision making is critical if we hope to develop well-rounded leaders who are prepared to engage in the activity of leading others.

\section{Review of Related Scholarship}

The reality is that true skill development (e.g., playing soccer, cooking, firefighting, becoming a black belt in karate, flying a plane, conducting CPR) requires deliberate practice (see Ericsson \& Pool, 2016) and the current paradigm of leadership learning and education is not designed to yield these outcomes. In reality, leadership learning and education needs a practice field. A place like the kitchen for a chef or stage for an actor where men and women can practice with an opportunity to repeat, receive coaching/feedback, and work on skills outside of their current ability levels (Ericsson, Krampe, \& Tesch-Römer, 1993; Ericsson, Prietula \& Cokely, 2007). One stream of research with a number of tangible lessons for leadership education is the expertise literature. Individuals working in this ream (a branch of psychology) have gone to great lengths to research not only what separates an expert from a novice (in any domain) but also how experts are trained and developed. When it comes to the questions of "what" separates experts from novices the distinctions are fairly straight forward. Experts know more about the domain, better see patterns and chunks of information, plan better interventions, and skillfully intervene more often than novices (Allen, Miguel, \& Martin, 2014).

Regarding the question of how experts are developed, Ericsson and his colleagues have determined that it is deliberate practice that separates experts from novices. In their book Peak, Ericsson and Pool (2016) outline several elements of deliberate practice which, when juxtaposed with the clear majority of leadership education, suggests a lot of opportunity for exploration and growth. According to Ericsson and Pool (2016), Deliberate Practice...

1. "requires a field that is already reasonably developed - that is, a field in which the best performers have attained a level of performance that clearly sets them apart from people who are just entering the field" (p. 98). Ericsson and Pool also emphasize the need for objective criteria upon which superior performers can be judged.

2. "requires a teacher who can provide practice activities designed to help a student improve his or her performance...in particular, deliberate practice is informed and guided by the best performers' accomplishments and by an understanding of what these expert performers do to excel. Deliberate practice is purposeful practice that knows where it is going and how to get there" (p. 99).

3. "develops skills that other people have already figured out how to do and for which effective training techniques have been established" and has "teachers to provide beginners with the correct fundamental skills in order to minimize the chances that the student will have to relearn those fundamentals skills later when at a more advanced level" (p. 99).

4. Requires a practice regimen "that should be designed and overseen by a teacher or coach who is familiar with the abilities of expert performers and how those abilities can be best developed" (p. 99)

5. 'takes place outside one's comfort zone and requires a student to constantly try things that are just beyond his or her current abilities. Thus, it demands near-maximal effort, which is generally not enjoyable" (p. 99). 
6. "involves well-defined, specific goals and often involves some aspect of the target performance; it is not aimed at some vague overall improvement. Once an overall goal has been set, a teacher or coach will develop a plan for making a series of small changes that will add up to the desired, larger change" (p. 99).

7. 'requires a person's full attention and conscious actions. It isn't enough to simply follow a teacher's or coach's directions. The student must concentrate on the specific goal for his or her practice activity so that adjustments can be made to control practice" (p. 99).

8. "involves feedback and modifications of efforts in response to that feedback. Early in the training process much of the feedback will come from the teacher or coach, who will monitor progress, point out problems, and way to address those problems" (p. 99)

9. "both produces and depends on effective mental representations. Improving performance goes hand in hand with improving mental representations; as one's performance improves, the representations become more detailed and effective, in turn making it possible to improve even more. Mental representations make it possible to monitor how one is doing, both in practice and in actual performance. They show the right way to do something and allow one to notice when doing something wrong and to correct it” (pp. 99-100).

While CLC curriculum designers have not yet addressed all nine of Ericsson and Pool's components of deliberate practice, we are working to design learning interventions that more closely mirror learning experiences that lead to expertise (Allen, Schwartz, \& Jenkins, 2017). For instance, we have developed clear processes for activities such as negotiation, conflict management, presentation skills, ethical decision making, and problem solving. Along with these processes we have developed video tutorials, learning materials, and teaching tips. We have also developed skill sheets (Brennan \& Braslow, 1995) that a leadership educator can use to assess performance. In the near future we will video exceptional performers so other students and educators have exemplars that they can turn to when learning the material.

\section{Description of the Practice}

After reading Ericsson and Pool's (2016) list, it is apparent that leadership educators have an opportunity to further define what is being "developed." This paper aligns with the work of Allen \& Shehane (2016) who suggests the following:

The definition of leadership training aligns closely with the tenants of behaviorism and is most concerned with a participant knowing how to display a skill or family of skills (competencies). This dimension is the Achilles heel of leadership learning and stems from a lack of a true practice field for growth. In addition, there is little agreement or understanding of the specific skills individuals should focus upon to be a more effective leader. Topics could include meeting management, facilitating discussion, decision making, negotiation, public speaking, and establishing vision. In this context: leadership training 'is proficiency in demonstrating specific skills associated with the activity of leadership.' (pp. 42-43) 
A common tool for assessing skill is the use of rubrics or skill sheets (Reddy \& Andrade, 2010). For instance, in the military, firefighting, k-12 education, and medical education, skill sheets are often displayed as checklists that outline desired behaviors (see National Registry of Emergency Medical Technicians, 2017). In the context of the CLC, skill sheets are used in the following manner. First, students are taught a relevant process. For instance, a simple decisionmaking model known as as SOLVE (Set roles, Outline the problem, List multiple strategies, Veer toward consensus, Evaluate results). The students commit the process to memory and are given a skill sheet that further outlines what "model" behavior looks like. Next, the leadership educator models the process for students so they can critique and evaluate performance. Then, students are placed in activities where they have a chance to "practice" leading the decisionmaking process themselves. At the conclusion of the activity, students receive feedback (coaching) from their instructor and peers on their performance.

\section{Skill Sheets in Use}

In the context of CLC, skills sheets are operationalized in a couple ways. First, they support certain components of curriculum which is integrative in nature (Boyer, 1990). The curriculum covers topics such as leadership/followership styles, ethical decision making, navigating difficult conversations, delegation, attributes of effective teams, and stressors. This content is presented as easy to remember acronyms and each is supported with: a description, a corresponding video, links to external videos/articles, supporting quotes, and references. For instance, a coach may be teaching CLC's problem solving model, SOLVE. This curriculum is explained to participants in the following manner:

A core activity of leadership is problem solving. The SOLVE acronym provides a simple model to help the leader and team navigate the challenges ahead. First, it's critical to set roles - who will lead? Who will keep time? What role will each person take in the activity? Next it's important to outline the problem. This means that the group has a clear understanding of the task at hand. A hallmark of this stage is there are a number of questions as the group tries to truly understand what it's trying to accomplish. Once the group has a clear understanding of the task's parameters, it can begin listing multiple strategies for completion. Once multiple strategies have been listed, the group can veer toward consensus and continue to evaluate results even as they implement the chosen strategy. It's not rare that the group will need to re-adjust if the chosen approach is not working. It's important to note that this process does not need to take a great deal of time. A skilled leader will move the group quickly through the process and have an acute awareness when the group (or certain members) has skipped a step or has not given a phase enough time and attention.

After sharing the content for SOLVE, the coach may choose to move the group into an activity such as the "Pringles Ringle." The "Pringles Ringle," an activity used in the 2017 CLC regional competitions, is designed to help participants begin to operationalize what has been learned. Jointly, the SOLVE Skill Sheet can help the coach provide feedback and gauge progress. The coach can also use the skill sheet for peer feedback after the activity has concluded. 


\section{Discussion of Outcomes/Results}

The authors have been exploring and experimenting with the notion of deliberate practice for about three years. There is initial support for our efforts in the context of a graduate leadership course (Martin \& Allen, 2016). Likewise, we have conducted some initial research on how the process impacts a student's motivation to lead and leadership self-efficacy (Chan \& Drasgow, 2001). We have also partnered with an external evaluator who will coordinate our longitudinal efforts to measure development and growth among participants. This information will be published and used to improve the experience for coaches and participants. Likewise, initial results will be published in an upcoming Symposium in the Journal of Leadership Studies (in press).

\section{Reflections}

The authors have seen promising results based on two-plus years of experience using rubrics/skill sheets and are now moving to empirical research. And while much work is needed, we are confident that deliberate practice and skill sheets are an important step in moving beyond cognitive and humanistic models of leadership learning and education (Allen \& Shehane, 2016).

In our work with students, we have made four primary observations about use of skill sheets in leadership education. First, all items on a skill sheet must be able to be verbalized or observed. During the course of an activity, it can be difficult to get inside the head of a student leading an activity so we have learned over the course of time, to encourage them to verbalize certain tasks so we know that they are working with a level of intentionality. For instance, a student may say, "I think we have brainstormed enough options, let's veer toward consensus and chose our best option." This statement displays a level of intentionality on the part of the leader. A second observation is that there is a strong need to video a student's performance. Oftentimes, a student (and even their peers) will think he or she displayed a behavior when they did not. Having a video not only helps the student see their strengths and areas for development, it can validate the feedback of the coach (or peers). A third observation is that leadership educators need some experience and practice with skill sheets. Most leadership educators have not been trained on the use of skill sheets in the classroom, and it is a different type of educational intervention than conceptual or humanistic approaches to leadership education. How an educator uses time, organizes the learning, and debriefs an activity through the lens of the skills sheet will take some adjustments. A final observation is that using skill sheets takes a great deal of time. Not only do students need to memorize and learn the content (similar to knowing the steps of CPR), providing the time and space for each individual to practice and test can be a scheduling challenge. Leadership educators need to re-think the design a typical class period or workshop. The good news is that when done well, students and educators can see improvement and growth - this can be quantified by conducting pre and post assessment with the use of video and skill sheets.

\section{Recommendations}

We contend that as a field, we have done well at designing cognitive (e.g., conceptual understanding, theory, cognitive understanding) and humanistic educational interventions (e.g., clarifying values, self-awareness, personal growth and development) and it is time to address the dimension of skill-building. Would you want a well-educated and self-aware physician with low 
levels of skill to conduct surgery on you? Will a well-educated, low-skill, and self-aware soccer player do well in a game? We feel in both examples they would be missing a critical dimension of the learning.

We recommend that leadership educators begin using skill sheets as a way to truly build skill in students. Likewise, we recommend that leadership educators incorporate the tenants of deliberate practice as one way to train and develop leadership. By doing so, we will be developing a more well-rounded leader.

\section{References}

Allen, S. J., Schwartz, A. J., \& Jenkins, D. M. (2017). Collegiate leadership competition: An opportunity for deliberate practice on the road to expertise. In S. Kempster, A. F. Turner, \& G. Edwards (Eds.) Field guide to leadership development (29-43). Cheltenham, UK: Edward Elgar Publishing.

Allen, S. J., \& Shehane, M. R. (2016). Exploring the Language of Leadership Learning and Education. New Directions for Student Leadership, 2016: 35-49. San Francisco: JosseyBass.

Allen, S. J., Miguel, R., Martin, B. A. (2014). Know, see, plan, do: A model for curriculum design in leadership development. SAM Advanced Management Journal, 72(2), 26-38.

Andenoro, A. C., Allen, S. J., Haber-Curran, P., Jenkins, D. M., Sowcik, M., Dugan, J. P., \& Osteen, L. (2013). National leadership education research agenda 2013-2018: Providing strategic direction for the field of leadership education. Retrieved from Association of Leadership Educators website: http://leadershipeducators.org/ResearchAgenda

Boyer, E. (1990). Scholarship reconsidered: Priorities of the professoriate. (Eric Document Reproduction Service No. ED326149. Retrieved May 5, 2009 from ERIC database: http://eric.ed.gov/ERICWebPortal/custom/portlets/recordDetails/detailmin i.jsp?_nfpb=true\&_\&ERICExtSearch_SearchValue_0=ED326149\&ERIC ExtSearch_SearchType_0=no\&accno=ED326149

Brennan, R. T., \& Braslow, A. (1995). Skill mastery in cardiopulmonary resuscitation training classes. The American journal of emergency medicine, 13(5), 505-508.

Chan, K. Y., \& Drasgow, F. (2001). Toward a theory of individual differences and leadership: understanding the motivation to lead. Journal of Applied Psychology, 86(3), 481.

Ericsson, K. A., Pool, R. (2016). Peak: Secrets from the new science of success. New York, NY: Houghton Mifflin Harcourt. 
Ericsson, K. A., Krampe, R. T., \& Tesch-Römer, C. (1993). The role of deliberate practice in the acquisition of expert performance. Psychological Review, 100(3), 363-406.

Ericsson, K. A., Prietula, M. J., \& Cokely, E. T. (2007). The making of an expert. Harvard Business Review, 85, 114-121.

Martin, B. A., \& Allen, S. J. (2016). Empirical Test of the Know, See, Plan, Do Model for Curriculum Design in Leadership Education. Journal of Leadership Education, 15(4), 132-143.

National Registry of Emergency Medical Technicians (2017). Psychomotor exams. Retrieved from https://www.nremt.org/rwd/public/document/psychomotor-exam

Reddy, Y. M., \& Andrade, H. (2010). A review of rubric use in higher education. Assessment \& evaluation in higher education, 35(4), 435-448.

\section{Author Biographies}

Scott J. Allen, Ph.D., is Associate Professor of Management at John Carroll University and co-founder of the Collegiate Leadership Competition. He has published more than 45 book chapters and peer-reviewed journal articles. He is a co-author of Emotionally Intelligent Leadership: A Guide for College Students and the corresponding resources. His email address is: sallen@jcu.edu

Dan Jenkins, Ph.D., is Chair and Associate Professor of Leadership \& Organizational Studies at the University of Southern Maine. He received his doctorate in Curriculum \& Instruction from the University of South Florida. Dan has published more than 30 peer-reviewed articles and book chapters and facilitated dozens of workshops around the world on leadership education, pedagogy, curriculum, and course design. Dan is a past chair of the ILA Leadership Education Member Interest Group, co-chair of the ILA Leadership Education Academy, and has served on the boards of the Association of Leadership Educators and Collegiate Leadership Competition. He can be reached at daniel.m.jenkins@maine.edu.

Bela Krizanovic, MBA, is the executive director of Collegiate Leadership Competition. Bela has been instrumental in turning the original vision into reality and is responsible for all day-to-day operations, and implementation of strategic initiatives such as regional expansion, corporate relationships, and curriculum design/development. Bela attended John Carroll University where she earned a degree in psychology and her MBA. She can be reached at bela@collegiateleader.org. 